\title{
Model calculations of posterior reliability indicators for the proposal of the maintenance system
}

\author{
Jana Galliková ${ }^{1, *}$, Vladimir Stuchlý ${ }^{1}$, Roman Poprocký ${ }^{1}$, Peter Volna $^{1}$ \\ ${ }^{1}$ University of Žilina, Faculty of Mechanical Engineering, Department of Transport and Handling \\ machines, Univerzitná 1, 01026 Žilina
}

\begin{abstract}
Designing the content and scale of maintenance of machines and equipment by a priori and posterior reliability methods in considered crucial to reducing the cost of the machine's life cycle, maintaining high operational readiness and reducing the consequences of failures. In the presented paper, attention is paid to the analysis of the calculation methods of posterior reliability for calculation indicators of reliability and to the use of the specified Weibull model for reliability calculations. The obtained results are further developed for models of optimal process calculations to perform scheduled maintenance interventions. Calculations of the other RAMS (reliability, availability, maintainability and safety) indicators that are critical to the design of an optimal engineering design with regard to maintenance and which do not receive sufficient attention in technical practice are also assessed.
\end{abstract}

Keywords: maintenance, reliability methods, Weibull model for reliability

\section{Introduction}

Analysis of individual failures is the specified failure of functional units and subsequently the reliability of the most distorted parts of electrical multiple unit series 671 is evaluated using the Weibull probability of distribution, which is a general probability distribution for determining the reliability of the mechanical components of the track-side vehicle. Based on these facts, it is then possible to optimize the vehicle maintenance system and to propose new approaches to care and secure reliability and especially passenger comfort $[1,2]$.

\section{Description of the monitored object}

The electric multiple unit 671 allows multiple control of the train set, which can consist of a maximum of three vehicles. In Fig. 1 we can see EMU 671 photo (driveway) running in Fig.1. Made to ensure a comfortable long-distance ride of $1,435 \mathrm{~mm}$. The power supply is also provided by a voltage system of $3 \mathrm{kV}$ DC as well as $25 \mathrm{kV} / 50 \mathrm{~Hz} \mathrm{AC}$.

\footnotetext{
* Corresponding author: jana.gallikova@fstroj.uniza.sk

Reviewers: Ivan Kuric, Bohuš Leitner
} 


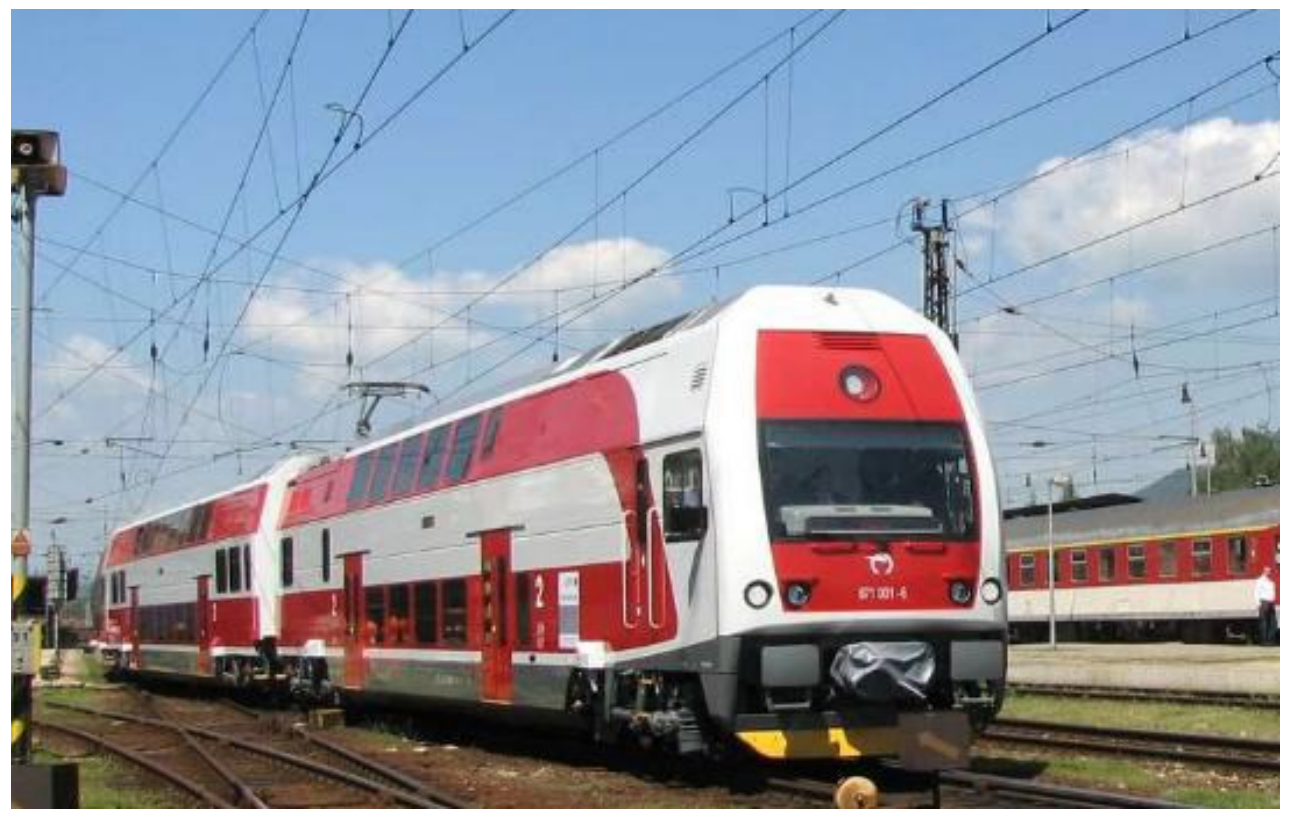

Fig. 1. Electric multiple unit series 671 (EMU 671)

\subsection{Overview of HDV 671 maintenance}

Technical capability of EMU in operation is maintained by maintenance. Periodic maintenance is the foundation of maintenance systems and consists of regularly alternating maintenance stages, the main feature of which is the prevention of failure.

They are:

- In operation servicing,

- minor inspection,

- major inspection,

- main repair,

- regular technical inspections.

Periodic maintenance includes the activities:

- Defectoscopy,

- diagnostic measurements and prophylactic controls,

- repair of the wheel drive profile (turning, turning)

- inspections and pressure tests of pressure vessels,

- preparation of the vehicle for winter / summer operation,

- revision of electrical equipment,

- vehicle weighing - checking and adjusting wheel pressure on the track,

- transformer oil exchange, of operating fluids.

Non-periodic maintenance includes the following maintenance steps:

- Scheduled repairs, includes:

- checking and setting of vehicle technical parameters (e.g. test site, dry or water resistance),

- checking the lateral clearance when pivoting the chassis to EMU cabinet frame,

- preservation and decontamination of EMU, 
- exchange of two-wheelers,

- exchange of hoops and full wheels,

- unplanned repair performed in periodic maintenance,

- unplanned repair performed separately, i.e. beyond the periodic maintenance.

In addition to periodic and non-periodic maintenance, construction changes (reconstruction, modernization, operational modifications) are performed on locomotives.

For locomotive delivery to the operating servicing and to a minor inspection, the kilometric norms with the permitted margin according to the ZSSK regulations apply. The upper limit is mandatory and must not be exceeded $[3,4,5]$.

\subsection{Methodology of following reliability of EMU 671}

The most reliable results of the reliability monitoring are the results obtained by statistical methods if the primary data are recorded directly for the purpose of establishing reliability indicators by statistical methods. However, it is not excluded to use as a source of information also data recorded for another purpose: details of repairs performed, defects found during regular maintenance interventions, etc.

We will create a form that can also be used as a maintenance record. For this reason, we used the correction book form as the basis for the proposal. The information contained in the repair book is recorded in the form. The following may be considered as the most important information's:

- the number of the propelling vehicle,

- date of decommissioning of the vehicle,

- description of the fault,

- the date of return to service.

For the subsequent evaluation of the initial information, the necessary data can be directly recorded via MS Excel.

\section{Engine failures}

In statistical evaluation, it is always necessary to process a large amount of information. Based on available data from ZSSK Slovakia, we have developed a list of individual types of repairs on the individual components of the vehicle on the EMU 671.

As a decision-making tool, we used Pareto's analysis, which showed that as the first failure we will analyse the occurrence of repair of trolley failures (Fig. 2). High repairs occur also in parts such as electrical equipment, collector, compressor, brake $[6,7,8]$. 


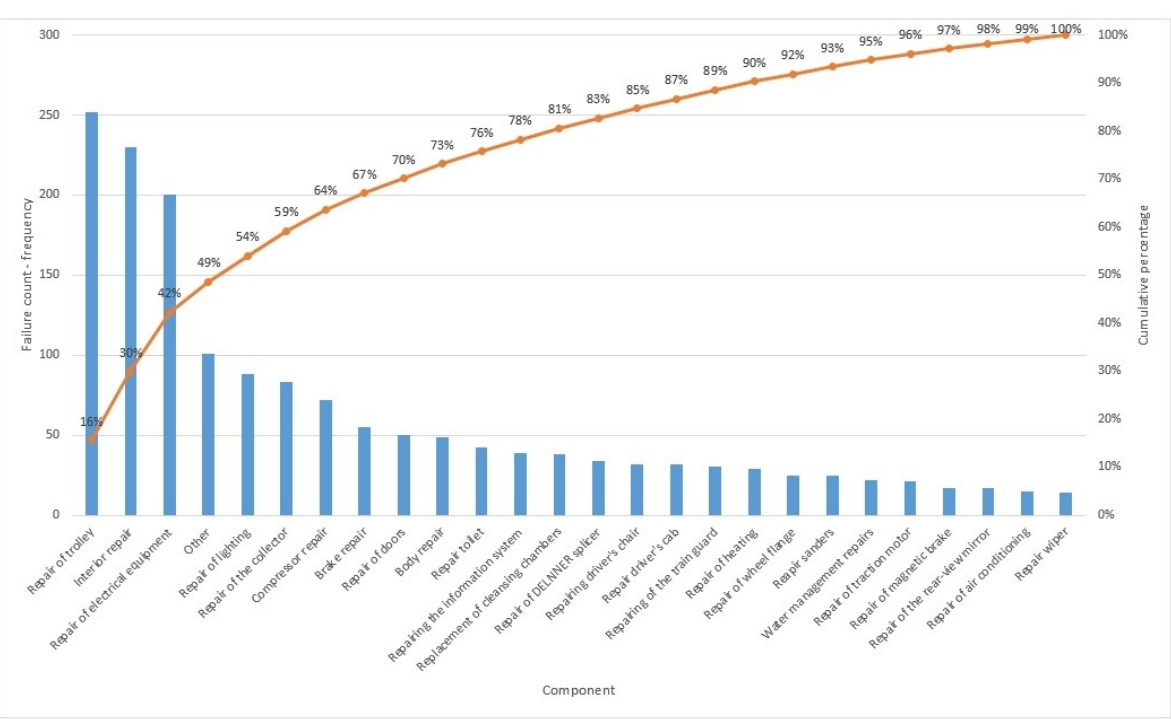

Fig. 2. Pareto's analysis of failures at EMU 671

\section{Statistical evaluation of reliability}

\subsection{Regression curve}

The obtained and classified data was subjected to a regression analysis. Table 1 shows a part of summary input and calculated values.

Table 1. Analysis of trolley failures - preparation of calculation

\begin{tabular}{|c|c|c|c|c|c|}
\hline $\mathrm{Ti}$ & Component & MEDIAN RANK & $1 /(1-\mathrm{MR})$ & $\ln [\ln (1 /(1-M R))]$ & $\ln \left(T_{i}\right)$ \\
\hline 4 & 1 & 0,002773376 & 1,00278109 & $-5,886301782$ & 1,38629436 \\
\hline 6 & 2 & 0,006735341 & 1,00678101 & $-4,99700972$ & 1,79175947 \\
\hline 9 & 3 & 0,010697306 & 1,01081298 & $-4,53239071$ & 2,19722458 \\
\hline 9 & 4 & 0,014659271 & 1,01487736 & $-4,215307508$ & 2,19722458 \\
\hline 19 & 5 & 0,018621236 & 1,01897457 & $-3,974068946$ & 2,94443898 \\
\hline 20 & 6 & 0,022583201 & 1,02310499 & $-3,779149642$ & 2,99573227 \\
\hline 29 & 7 & 0,026545166 & 1,02726903 & $-3,615485838$ & 3,36729583 \\
\hline 32 & 8 & 0,030507132 & 1,0314671 & $-3,474343717$ & 3,4657359 \\
\hline 36 & 9 & 0,034469097 & 1,03569963 & $-3,350204786$ & 3,58351894 \\
\hline 37 & 10 & 0,038431062 & 1,03996704 & $-3,239358726$ & 3,61091791 \\
\hline 38 & 11 & 0,042393027 & 1,04426976 & $-3,139190651$ & 3,63758616 \\
\hline 46 & 12 & 0,046354992 & 1,04860823 & $-3,047788261$ & 3,8286414 \\
\hline 55 & 13 & 0,050316957 & 1,0529829 & $-2,963710696$ & 4,00733319 \\
\hline 56 & 14 & 0,054278922 & 1,05739422 & $-2,885845266$ & 4,02535169 \\
\hline 58 & 15 & 0,058240887 & 1,06184266 & $-2,813314783$ & 4,06044301 \\
\hline 60 & 16 & 0,062202853 & 1,06632869 & $-2,745415456$ & 4,09434456 \\
\hline
\end{tabular}

The first column (Ti) of Table 1 contains the days when the train driver malfunctioned. The second column (Component) contains the number of failures. In the third column (MEDIAN RANK - MR) for calculating the share estimation, the formula is used: 


$$
p=((i-0,3) \div(n+0,4))
$$

where $i$ is a sequence of failures and $\mathrm{n}$ is the total number of observed failuress, with the number 1 being from the "Component" column. In the fourth column, the formula is used:

$$
1 \div(1-M R)
$$

In the fifth column for calculating the value, the double natural logarithm is used, then the formula:

$$
\ln [\ln (1 \div(1-M R))]
$$

In the last column, the following formula is used to calculate the value:

$$
\ln (T i)
$$

We plot the values from the fifth and sixth columns in the graph (Fig. 3), where the orange curve represents the real course and the straight line represents the linear course of the $\ln (\ln (1 / 1-(M R))$ dependence of $\ln (T i)$.

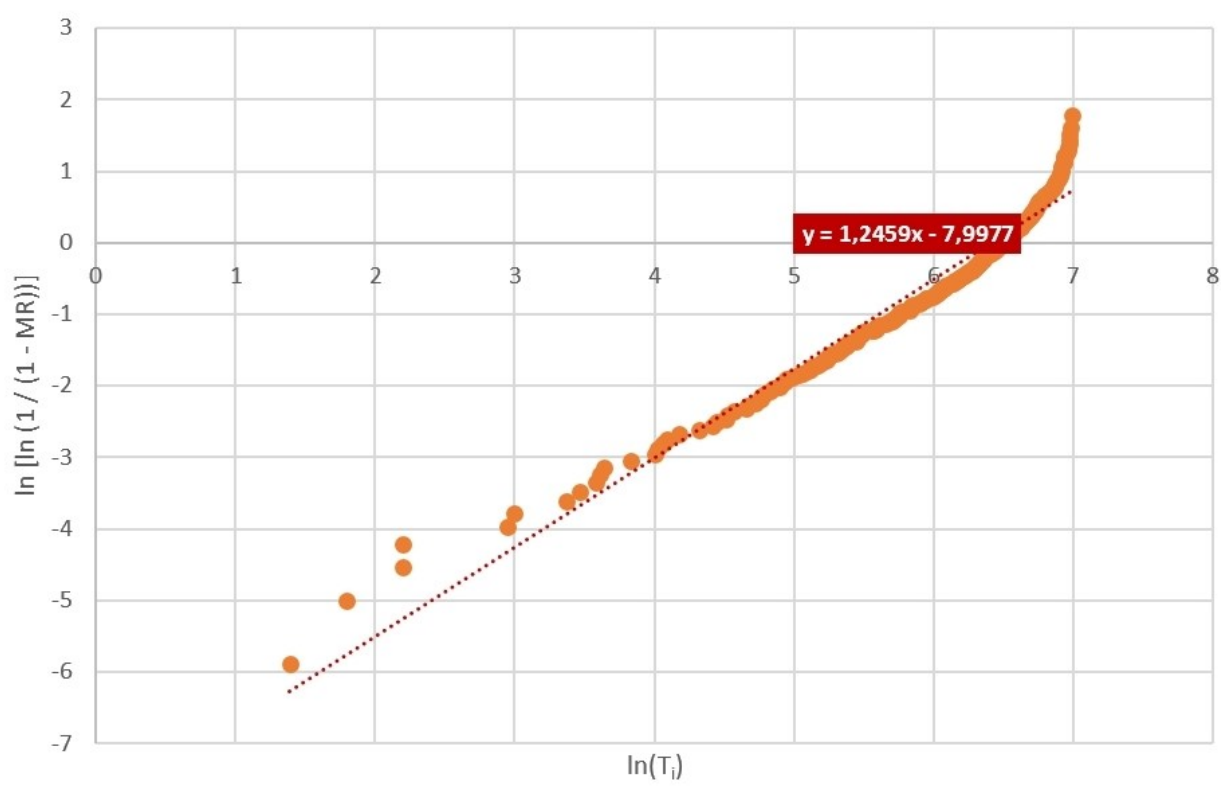

Fig. 3 Line fit pilot for trolley

After plotting dependence, the line equation, whose general shape is [8]:

$$
y=m x+b
$$

\subsection{Weibull's model}

In order to statistically model reliability in engineering, we will use the Weibull's model of probability. Weibull's distribution is used in cases where reliability depends on age, hours 
worked, or operating cycles. In terms of reliability, Weibull's distribution is used to determine reliability indicators that are important information needed to predict, evaluate and compare the life of products, evaluate construction and technology changes, compare alternative designs or technologies, compare the life of products of different technologies or different manufacturers, creating a warranty policy in a proactive approach to inventory management or repairs planning [9].

Weibull's distribution can be transformed to the form of the line equation:

$$
\mathrm{F}(\mathrm{x})=1-\mathrm{e}^{-\left(\frac{\mathrm{x}}{\alpha}\right)^{\beta}}
$$

where: $\mathrm{F}(\mathrm{x})$ - cumulative distribution function,

$\alpha$ - scale parameter of the function (characteristic life),

$\beta$ - shape parameter of the distribution.

$$
\begin{gathered}
1-\mathrm{F}(\mathrm{x})=\mathrm{e}^{-\left(\frac{\mathrm{x}}{\alpha}\right)^{\beta}} \\
\ln (1-\mathrm{F}(\mathrm{x}))=\left[-\left(\frac{\mathrm{x}}{\alpha}\right)\right]^{\beta} \\
\ln \left[\ln \left(\frac{1}{1-F(x)}\right)\right]=\beta \ln \left(\frac{x}{\alpha}\right) \\
\ln \left[\ln \left(\frac{1}{1-F(x)}\right)\right]=\beta \ln x-\beta \ln \alpha
\end{gathered}
$$

By comparing this formula with a simple equation we can see that the left side of the equation corresponds to $y$, $\ln x$ corresponding to $x, \beta$ corresponds to $m$ and $\beta \ln \alpha$ corresponds to $b$. Therefore, if we want to perform a linear regression, we need to know the parameter estimation. Estimating the Weibull parameter $\beta$ comes directly from the straight line. Estimate for parameter $\alpha$ must be calculated [10-12]:

$$
\alpha=e^{-\left(\frac{b}{\beta}\right)}
$$

From the line equation: $y=1.2459-7.9977$ we get $\beta=1.2459$ where we can calculate the parameter:

$$
\alpha=e^{-\left(\frac{7,9977}{1,2459}\right)}=613.4185
$$

I choose number 0,9 as the value of reliability $R(x)$, while the probability of failure $Q(x)$ we can calculate:

$$
Q(x)=1-R(x)
$$


For calculation of the cycle $(\mathrm{km})$ we use the formula:

$$
\begin{gathered}
\text { Cycle }(\text { days })=\alpha \cdot(-\ln R(x))^{\frac{1}{\beta}} \\
101 \text { days }=613,4185 \cdot(-\ln 0,9)^{\frac{1}{1,2459}}
\end{gathered}
$$

The resulting value means the probability of failure the trolley $10 \%$ trolley occurs every 101 days.

Based on the Weibull model, we processed a calculation whose graphical output can be seen in the figure. There is a reliability function $R(x)$, the probability of failure $Q(x)$, failure rate $\lambda(x)$, and the probability density function $f(x)$ (Fig. 4).

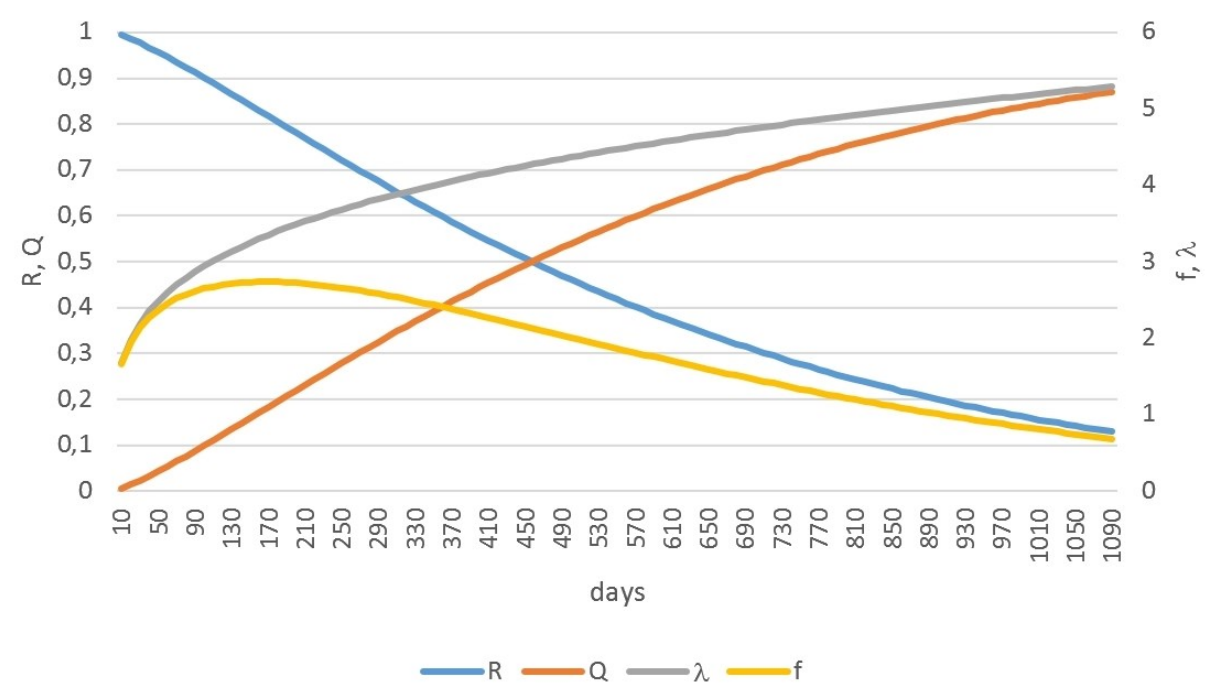

Fig. 4 Reliability indicators for Trolley

\subsection{Use the Analysis ToolPak to perform complex data analysis in Excel}

If you need to develop complex statistical or engineering analyses, you can save steps and time by using the Analysis ToolPak. You provide the data and parameters for each analysis, and the tool uses the appropriate statistical or engineering macro functions to calculate and display the results in an output table. Some tools generate charts in addition to output tables.

The data analysis functions can be used on only one worksheet at a time. When you perform data analysis on grouped worksheets, results will appear on the first worksheet and empty formatted tables will appear on the remaining worksheets. To perform data analysis on the remainder of the worksheets, recalculate the analysis tool for each worksheet.

The Regression analysis tool performs linear regression analysis by using the "least squares" method to fit a line through a set of observations. You can analyse how a single dependent variable is affected by the values of one or more independent variables. For example, you can analyse how an athlete's performance is affected by such factors as age, height, and weight. You can apportion shares in the performance measure to each of these three factors, based on a set of performance data, and then use the results to predict the performance of a new, untested athlete. The Regression tool uses the worksheet function LINEST (Fig. 5). 
SUMMARY OUTPUT

\begin{tabular}{|c|c|c|c|}
\hline$m=\beta$ & b & \multicolumn{2}{|c|}{ Regression Statistics } \\
\hline 1,2459355 & $-7,99772$ & Multiple R & 0,980603 \\
\hline 0,0157505 & 0,09515 & R Square & 0,961583 \\
\hline & & Adjusted R Square & 0,961429 \\
\hline$\alpha$ & & Standard Error & 0,248038 \\
\hline 613,41846 & & Observations & 252 \\
\hline
\end{tabular}

R Ti

ANOVA

Reliability Days

\begin{tabular}{|c|c|}
\hline 0,01 & 2090 \\
\hline 0,1 & 1198 \\
\hline 0,5 & 457 \\
\hline 0,9 & 101 \\
\hline 0,99 & 15 \\
\hline
\end{tabular}

\begin{tabular}{lrrrr} 
& \multicolumn{1}{c}{$d f$} & \multicolumn{1}{c}{ SS } & MS \\
\hline Regression & 1 & 384,9813071 & 384,9813071 \\
\hline Residual & 250 & 15,38067201 & 0,061522688 \\
\hline Total & 251 & 400,3619791 & \\
\hline & & & \\
\hline & Coefficients & Standard Error & t Stat \\
\hline Intercept & $-7,997719$ & 0,095152689 & $-84,0514233$ \\
\hline In (Ti) & 1,245935 & 0,015750465 & 79,10467857 \\
\hline
\end{tabular}

Beta (or Shape Parameter) $=1,25$

Alpha (or Characteristic Life) $=613,42$

Fig. 5 Using the function LINEST in MS Excel

The LINEST function calculates the statistics for a line by using the "least squares" method to calculate a straight line that best fits your data, and then returns an array that describes the line. You can also combine LINEST with other functions to calculate the statistics for other types of models that are linear in the unknown parameters, including polynomial, logarithmic, exponential, and power series. Because this function returns an array of values, it must be entered as an array formula.

\subsection{Interpreting the results LINEST}

The Weibull shape parameter, called $\beta$, indicates whether the failure rate is increasing, constant or decreasing. And $\beta<1.0$ indicates that the product has a decreasing failure rate. This scenario is typical of "infant mortality" and indicates that the product is failing during its "burn-in" period. And $\beta=1.0$ indicates a constant failure rate. Frequently, components that have survived burn-in will subsequently exhibit a constant failure rate. And $\beta>1.0$ indicates an increasing failure rate. This is typical of products that are wearing out. Such is the case with the spring housings-both Trolley and Electrical equipment have $\beta$ values much higher than 1.0 equipment, i.e., they wear out.

The Weibull characteristic life, called, is a measure of the scale, or spread, in the distribution of data. It so happens that $\alpha$ equals the number of days at which 63.2 percent of the product has failed. In other words, for a Weibull distribution $(\mathrm{R}=0.368)$, regardless of the value of $\beta$. For example, with Trolley, about 37 percent of the Trolleys should survive at least 613.4185 days. 


\section{Conclusion}

In the paper, we tried to explain the basic use of Weibull's distribution in the EMU 671 failure analysis. In the first part we processed the basic description and defects of EMU 671. In the second part we analysed failures that occurred during the operation on the critical parts of unit.

An important parameter in failure analysis was the number of days until a failure occurred. Depending on the number of days, preventative maintenance may be performed by checking the condition or replacing the individual components in which failures occur, thus preventing the occurrence of the consequences of the failure.

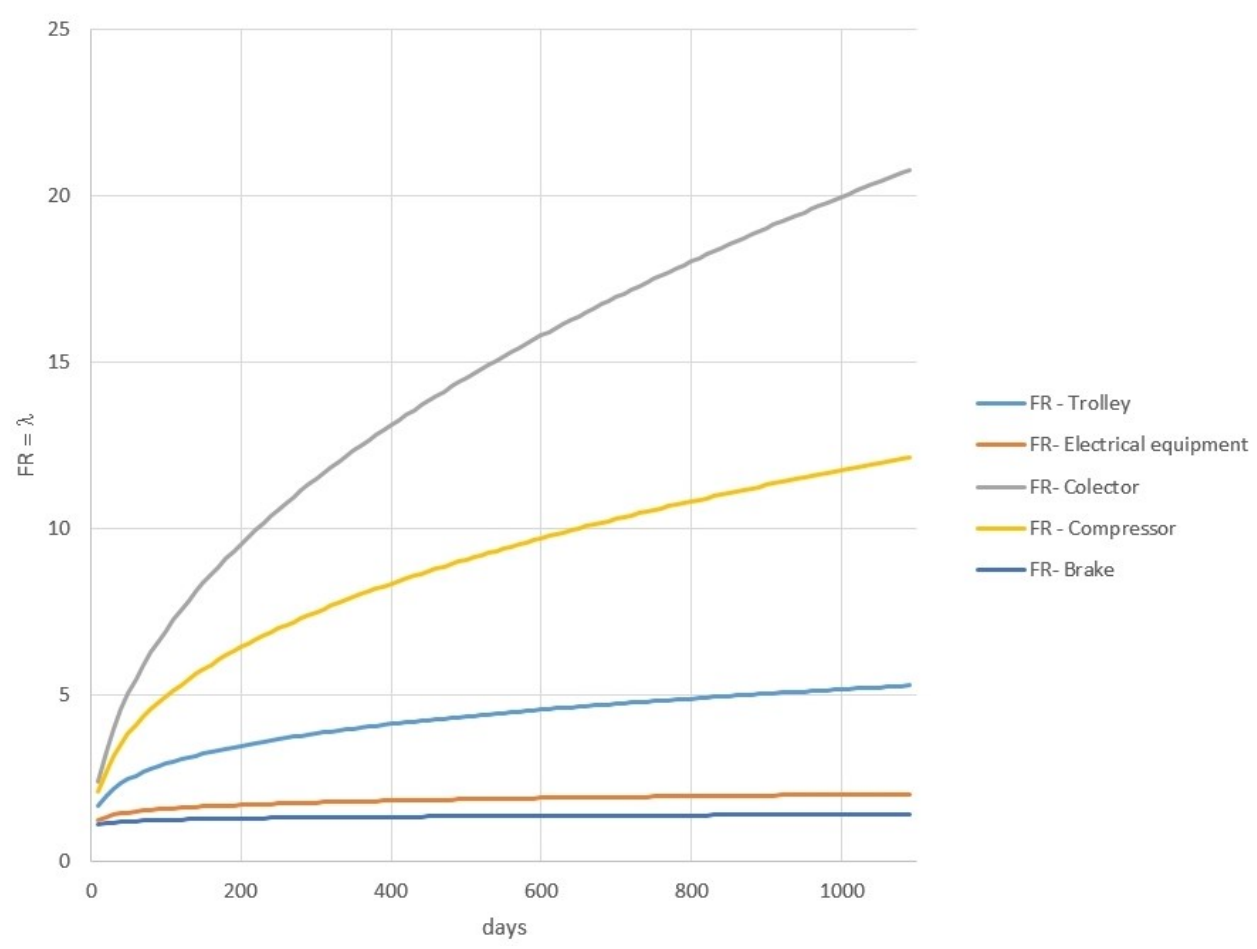

Fig. 6 Graph of failures rate

The graph (Fig. 6) shows failures rate that we can express on preventive maintenance of individual components. We see that it is not appropriate to define a planned preventive maintenance system in the case of the graphical course of the failure rate of the electrical equipment and brake because the increase of the fault intensity value is almost constant in the case of the trolley and compressor elements and it is advisable to consider planned preventive maintenance $[13,14]$.

This article was supported by the Scientific Grant Agency of the Ministry of Education of the Slovak Republic and the Slovak Academy of Sciences in project no. VEGA 1/0766/15 "Research sources of noise emissions from rail transport and ways of their effective reducing". 


\section{References}

1. J. Galliková, R. Poprocký, Maintenance according to the technical state with use of the enterprise asset management systems. Zeszyty naukowe Instytutu Pojazdów: Mechanika, ekologia, bezpieczeństwo, mechatronika 3 (103), (2015)

2. J. Galliková, R. Poprocký, P. Volna, Implementation of FMEA method in maintenance of semi-trailer combination. Diagnostyka 17 (4), (2016)

3. J. Grenčík, et all, Maintenance Management. Synergy of Theory and Practice. (1. vyd., Košice: Beki Design, 629 p., ISBN 978-80-89522-03-3, 2013)

4. F. Ruman, J. Grenčík, Proposal of new maintenance scheme of air brake system on semi-triler combination. Diagnostyka 16 (2), 11-19 (2015)

5. M. Klinko, J. Grenčík, Tilting body vehicles on Slovak railways - potential for use and parameters to be considered. Communications : Scientific Letters of the University of Žilina 10 (3), 45-49 (2008)

6. H. Pačaiová, Š. Markuliak, A. Nagyová, The importance of risk in management systems. (Košice, BEKI Design, s.r.o., 2016)

7. L. Kašiar, P. Zvolenský, D. Barta, L. Bavlna, P. Drozdziel, Diagnostics of electric motor of locomotive series 757. Diagnostyka 17 (3), 95-101 (2016)

8. H. Pacaiova, J. Grencik, G. Dravecky, Maintenance audit as a means for asset management improvement. Euromaintenance: conference proceedings: 30 May - 1 June, 2016: Athens, Greece, Athens: EFNMS, ISBN 978-618-82601-0-8, 463-469 (2016)

9. H. Pačaiová, J. Sinay, J. Glatz, Safety and risks of technical systems. (ISBN 978-80553-0180-8-60-30-10, Košice, Vienala Košice, 2009)

10. V. Stuchlý, P. Zvolenský, History and Presence of Maintenance Education at the Faculty of Engineering of the University of Žilina. Ǩizení \& údržba průmyslového podniku - Slovenský špeciál 6, (2016)

11. H. Pačajová, J. Grenčík, G. Dravecký, Maintenance audit as a means for asset management improvement. Euromaintenance: conference proceedings: ISBN 978-61882601-0-8., 463-469 (2016)

12. J. Dižo, M. Blatnický, Use of multibody system dynamics as a tool for rail vehicle behaviour diagnostics. Diagnostyka, science journal. Polish Society of Technical Diagnostics 17 (2), 9-16 (2016)

13. M. Rakyta, et all, Proactive approach to smart maintenance and logistics as a auxiliary and service processes in a company. Journal of applied engineering science 14 (4), 433-442 (2016)

14. M. Gregor, et all, Model of intelligent maintenance systems. Annals of DAAAM: proceedings of the 26th DAAAM international symposium on intelligent manufacturing and automation, [Online], 1097-1101 (2016) 